\title{
Association of beverage consumption with obesity in Mexican American children
}

\author{
Amy L Beck ${ }^{1, *}$, Jeanne Tschann ${ }^{2}$, Nancy F Butte ${ }^{3}$, Carlos Penilla ${ }^{2}$ and \\ Louise C Greenspan ${ }^{4}$ \\ 'Department of Pediatrics, University of California San Francisco, 3333 California Street - Suite 245, \\ Box 0503, San Francisco, CA 941 18, USA: ${ }^{2}$ Department of Psychiatry, University of California San Francisco, \\ San Francisco, CA, USA: ${ }^{3}$ Department of Pediatrics, Baylor College of Medicine, Houston, TX, USA: \\ ${ }^{4}$ Department of Pediatrics, Kaiser Permanente San Francisco, San Francisco, CA, USA
}

Submitted 5 July 2012: Final revision received 3 October 2012: Accepted 9 November 2012: First published online 11 January 2013

\begin{abstract}
Objective: To determine the association of beverage consumption with obesity in Mexican American school-aged children.

Design: Cross-sectional study using the baseline data from a cohort study. Mothers and children answered questions about the frequency and quantity of the child's consumption of soda, diet soda, other sugar-sweetened beverages, $100 \%$ fruit juice, milk and water. The questions were adapted from the Youth/ Adolescent FFQ. Children were weighed and measured. Data were collected on the following potential confounders: maternal BMI, household income, maternal education, maternal occupational status, maternal acculturation, child physical activity, child screen time and child fast-food consumption. Logistic regression was used to examine the association between servings $(240 \mathrm{ml})$ of each beverage per week and obesity (BMI $\geq 95$ th percentile).

Setting: Participants were recruited from among enrolees of the Kaiser Permanente Health Plan of Northern California. Data were collected via an in-home assessment.

Subjects: Mexican American children ( $n$ 319) aged 8-10 years.

Results: Among participants, 20\% were overweight and 31\% were obese. After controlling for potential confounders, consuming more servings of soda was associated with increased odds of obesity ( $\mathrm{OR}=1 \cdot 29 ; P<0 \cdot 001)$. Consuming more servings of flavoured milk per week was associated with lower odds of obesity ( $\mathrm{OR}=0 \cdot 88 ; P=0 \cdot 004)$. Consumption of other beverages was not associated with obesity in the multivariate model.

Conclusions: Discouraging soda consumption among Mexican American children may help reduce the high obesity rates in this population.
\end{abstract}

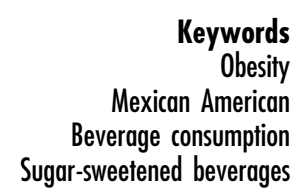

Obesity

Mexican American Sugar-sweetened beverages
Childhood obesity is epidemic in the USA and there are significant racial/ethnic disparities in obesity rates, with Latino children disproportionately affected ${ }^{(1)}$. The most recent National Health and Nutrition Examination Survey (NHANES) found that 39\% of Mexican American children aged $6-11$ years were overweight (BMI $\geq 85$ th percentile) and $22 \%$ were obese $(\mathrm{BMI} \geq 95 \text { th percentile })^{(1)}$. Childhood obesity significantly increases the risk of being obese in adulthood $^{(2)}$ and is also associated with numerous morbidities in childhood ${ }^{(3)}$. Consequently, it is crucial to understand the aetiology of childhood obesity in Mexican American children to improve the efficacy of prevention measures.

Of the dietary habits which may contribute to child obesity, beverage consumption is of particular interest. However, there are unanswered questions with respect to the effects of different beverages on obesity risk. Energy from sugar-sweetened beverages (SSB) now comprises nearly $10 \%$ of total energy intake for children in the USA, and the greatest increases in SSB consumption have been in minority youth ${ }^{(4)}$. Several studies have found an association between SSB consumption and obesity in children ${ }^{(5-8)}$. However, other studies have found no association $^{(9-11)}$, and recent review articles and metaanalyses differ in their conclusions on the strength of the evidence linking SSB consumption to obesity in children $^{(12-15)}$. With respect to beverages other than SSB, several observational and one experimental study found that the consumption of milk and other dairy products may be protective against obesity in children ${ }^{(16-20)}$; although other studies have found that dairy consumption has a neutral effect on childhood obesity ${ }^{(21)}$. Finally, while some studies have found that $100 \%$ fruit juice 
consumption is associated with obesity ${ }^{(18,22-24)}$, other studies have not confirmed this finding ${ }^{(25,26)}$.

Of the previous studies that have analysed the association between beverage consumption and obesity in Latino children, all but one were limited to children aged 6 years or younger and most examined a limited number of beverage categories ${ }^{(5,6,8,27,28)}$. We sought to broadly characterize the beverage consumption habits in a sample of Mexican American children aged 8-10 years and to determine whether beverage consumption was associated with obesity in this population.

\section{Experimental methods}

\section{Study design}

This was a cross-sectional study using baseline data collected on a cohort of Mexican American children aged 8-10 years living in the San Francisco Bay Area.

\section{Recruitment}

Participants were recruited from the membership lists of Kaiser Permanente of Northern California, an integrated health-care system. Parents of potential participants were sent letters introducing the study which included a stamped addressed refusal postcard to opt out of any further contact. After a 2-week waiting period, they received a telephone call from a trained bilingual research assistant and were screened for eligibility. If eligible, they were invited to participate in the study. Children were eligible to participate if they were between the ages of 8 and 10 years old, their mother was of Mexican origin (born in the USA or Mexico) and they had no major illnesses. There were no restrictions to study entry based on child's BMI. Of families screened and found eligible, $37 \%$ of mothers agreed to participate in the study. There were 326 total children enrolled and we have complete beverage consumption data for 319. Prior to entering the study, written informed consent was obtained from parents and assent was obtained from children. The study was conducted according to the guidelines laid down in the Declaration of Helsinki and all procedures involving human subjects were approved by the Committee on Human Research at the University of California San Francisco and the Institutional Review Board of Kaiser Permanente of Northern California.

\section{Data collection and measures}

The data for the study were collected during an in-home assessment with the mother and child on entrance to the study. The assessment was conducted by a bilingual research assistant, in the language of the participant's choice. The data were collected over a 2-year period during both the school year and summer months. The questions, adapted from the Youth/Adolescent FFQ ${ }^{(29)}$, provided more detailed beverage frequency and quantity information than previously existing validated questionnaires. To determine beverage consumption mothers were asked: (i) 'How many days per week does (child) have (beverage)?' (ii) 'On one of the days that (child) has (beverage), how much does he/she have altogether?' The child was present for the interview and assisted the mother in answering the questions. Based on the mother's response, the interviewer converted the amount described to liquid ounces ( 1 ounce $=30 \mathrm{ml}$ ). The interviewers had been previously trained on dietary recall procedures, which included converting commonly described quantities of beverages to an exact measure in ounces. Mothers were asked about regular soda, diet soda, other SSB (including fruit drinks, sports drinks, flavoured ice teas and other flavoured drinks containing sugar), $100 \%$ fruit juice, whole milk, $2 \%$ milk, $1 \%$ milk, skimmed milk, flavoured milk and plain water (tap or bottled). If a mother was unsure what category a particular beverage fit into, the interviewer provided clarification. For each beverage, average consumption in liquid ounces per week was determined by multiplying the number of days per week that the beverage was consumed by the typical volume consumed. This value was then divided by eight to determine the number of 8 ounce $(240 \mathrm{ml})$ servings per week. The interviewers also measured both children's and mother's height and weight during the in-home assessment, using standard procedures $^{(30)}$. Height and weight were measured in duplicate while the participant was wearing light indoor clothes and no shoes.

In addition to maternal BMI, other potential covariates that were measured included: child fast-food consumption, child screen time, child physical activity, maternal country of origin, maternal Spanish language use (as a measure of acculturation), maternal education, household income and the mother's occupational status if employed or formerly employed. To measure fast-food consumption, mothers were asked how often the child eats dinner at a fast-food restaurant, with options ranging from 'never or almost never' $(=1)$ to 'every day' $(=6)$. Mothers were also asked how often the child eats fast food for lunch on weekends, with answers ranging from 'never or almost never' $(=1)$ to ' 2 weekend days per week' $(=4)$. Child screen time was determined through an interview with the child ${ }^{(31)}$. For the most recent weekday and most recent weekend day, children were asked to quantify the total amount of time that they spent watching television, videos or DVDs, playing video games and playing on the computer (excluding homework). Child physical activity was determined by having children wear an Actical accelerometer (Mini-Mitter Co., Inc., Bend, OR, USA) for a $72 \mathrm{~h}$ period that captured activity on two weekdays and one weekend day. The accelerometers were fixed to an elastic belt with an adjustable buckle and positioned on the child above the iliac crest of the right hip. The accelerometer was worn at 
all times during the monitoring period except for when the participant was bathing. The accelerometer data were utilized to determine the child's percentage of time spent engaging in moderate-to-vigorous physical activity.

Acculturation was assessed with the Spanish Language Use subscale of the Bidimensional Acculturation Scale for Hispanics $(\alpha \text { for our sample }=0.94)^{(32)}$. Mothers reported the highest educational level that they had attained. The interviewers ranked the occupational status of mothers' employment using Hollingshead's (1975) scale which ranges from 1 (lowest, e.g. personal service worker) to 9 (highest, e.g. executive or major professional) ${ }^{(33)}$. To determine household income, mothers were asked to estimate annual pre-tax incomes of all individuals living in the home.

\section{Analysis}

Maternal BMI was calculated $\left(\mathrm{kg} / \mathrm{m}^{2}\right)$. Children's BMI was also calculated and converted to age- and gender-specific percentiles using the US National Center for Health Statistics growth charts ${ }^{(34)}$. Children's BMI was converted to a dichotomous variable of obese (BMI $\geq 95$ th percentile) or not. Mothers' responses to the questions on fast-food frequency for dinners and weekday lunches were summed together to create one fast-food frequency variable. Children's average daily screen time was created by averaging the weekend and weekday screen time.
All statistical analyses were performed using the statistical software package Stata version 12. We used univariate logistic regression to determine the relationship between beverage consumption and child obesity using the dichotomous variable of obese (BMI $\geq 95$ th percentile) or not as our outcome and a continuous variable of servings $(240 \mathrm{ml}$ servings) of each beverage per week as a predictor. We also examined the relationship of each potentially confounding covariate with child obesity. We retained beverage variables and covariates which were associated with obesity $(P<0 \cdot 1)$. We then entered the retained covariates, age and gender and the retained beverage variables in a multivariate logistic regression model.

\section{Results}

Complete beverage consumption and BMI results were available for 319 children. Table 1 presents demographic and behavioural characteristics of our sample. There were high rates of both overweight and obesity, with $51 \%$ of children above the 85th percentile for BMI and 31\% above the 95th percentile. Of mothers, 33\% were overweight $\left(\mathrm{BMI}=25 \cdot 0-29 \cdot 9 \mathrm{~kg} / \mathrm{m}^{2}\right)$ and $47 \%$ were obese $\left(\mathrm{BMI} \geq 30 \cdot 0 \mathrm{~kg} / \mathrm{m}^{2}\right)$. The percentage consuming regular soda, diet soda, other SSB (fruit drinks, flavored teas, flavoured waters and sports drinks), whole milk, $2 \%$ milk,

Table 1 Child, parental and household characteristics in a study examining the association of beverage consumption with obesity in Mexican American children ( $n$ 319) aged 8-10 years, San Francisco Bay Area, USA

\begin{tabular}{|c|c|c|c|}
\hline Variable & Mean & SD & $\%$ \\
\hline \multicolumn{4}{|l|}{ Child characteristics } \\
\hline Female & & & 53 \\
\hline Child age (years) & $9 \cdot 3$ & 0.9 & \\
\hline BMI percentile & $75 \cdot 0$ & $25 \cdot 6$ & \\
\hline $\mathrm{BMI} \geq 85$ th percentile & & & 51 \\
\hline $\mathrm{BMI} \geq 95$ th percentile & & & 31 \\
\hline \multicolumn{4}{|l|}{ Screen time $(\mathrm{min})$} \\
\hline Weekday & 139 & 120 & \\
\hline Weekend & 157 & 135 & \\
\hline \multicolumn{4}{|l|}{ Fast-food frequency } \\
\hline Never or almost never & & & 26 \\
\hline$\leq 3$ times/month & & & 22 \\
\hline 1 time/week & & & 26 \\
\hline$>1$ time/week & & & 26 \\
\hline \multicolumn{4}{|l|}{ Parental and household characteristics } \\
\hline Median household income (\$US) & 45000 & & \\
\hline Maternal BMI $\left(\mathrm{kg} / \mathrm{m}^{2}\right)$ & $30 \cdot 4$ & $6 \cdot 8$ & \\
\hline Overweight $\left(\mathrm{BMI}=25 \cdot 0-29 \cdot 9 \mathrm{~kg} / \mathrm{m}^{2}\right)$ & & & 33 \\
\hline Obese $\left(\mathrm{BMI} \geq 30 \cdot 0 \mathrm{~kg} / \mathrm{m}^{2}\right)$ & & & 47 \\
\hline \multicolumn{4}{|l|}{ Maternal education } \\
\hline$\leq 6$ th grade education & & & 19 \\
\hline 7th-11th grade education & & & 28 \\
\hline High-school graduate & & & 23 \\
\hline Education beyond high school & & & 29 \\
\hline Mothers born in Mexico & & & 78 \\
\hline Maternal occupational status (scale 1-9) & $3 \cdot 2$ & $2 \cdot 1$ & \\
\hline Maternal Spanish language use (scale 1-5) & $4 \cdot 2$ & $1 \cdot 1$ & \\
\hline \multicolumn{4}{|l|}{ Paternal ethnicity } \\
\hline Mexican & & & 85 \\
\hline Other Latino & & & 9 \\
\hline
\end{tabular}


$1 \%$ milk, skimmed milk, flavoured milk, 100\% fruit juice and water (tap or bottled) is presented in Fig. 1 and the mean weekly consumption of these beverages in servings $(240 \mathrm{ml})$ among children who reported consuming any is presented in Fig. 2. The beverages most commonly consumed were water and $100 \%$ fruit juice. Consumption of soda and other SSB was also common; $64 \%$ of children consumed soda and 69\% consumed other SSB. Most children $(87 \%)$ consumed either soda or another SSB. Nearly all (99\%) of the children consumed some form of milk, with $2 \%$ milk being the most common followed by flavoured milk. Only $9 \%$ of children consumed non-fat milk. Mean weekly consumption of milk (all forms) was $3 \cdot 15$ litres. The correlations between soda consumption and consumption of the other beverages are displayed in Table 2 .

In univariate analyses, consumption of soda, 2\% milk and water were associated with increased odds of obesity; and consumption of whole milk and flavoured milk were associated with lower odds of obesity (Table 3). Consumption of diet soda, other SSB, $100 \%$ fruit juice, $1 \%$ milk and skimmed milk were not associated with

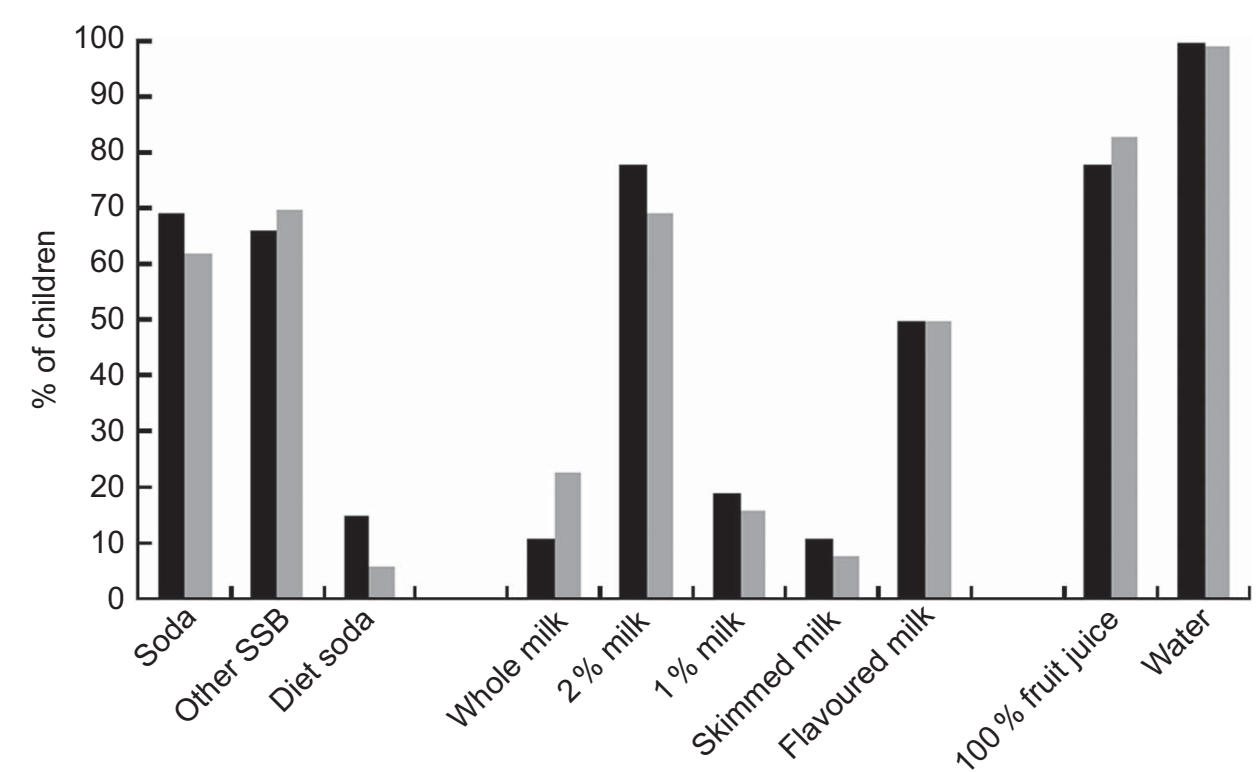

Fig. 1 Percentage of obese $(\square)$ and non-obese $(\square$ ) participants who consume each surveyed beverage in a typical week; Mexican American children ( $n$ 319) aged 8-10 years, San Francisco Bay Area, USA (SSB, sugar-sweetened beverages)

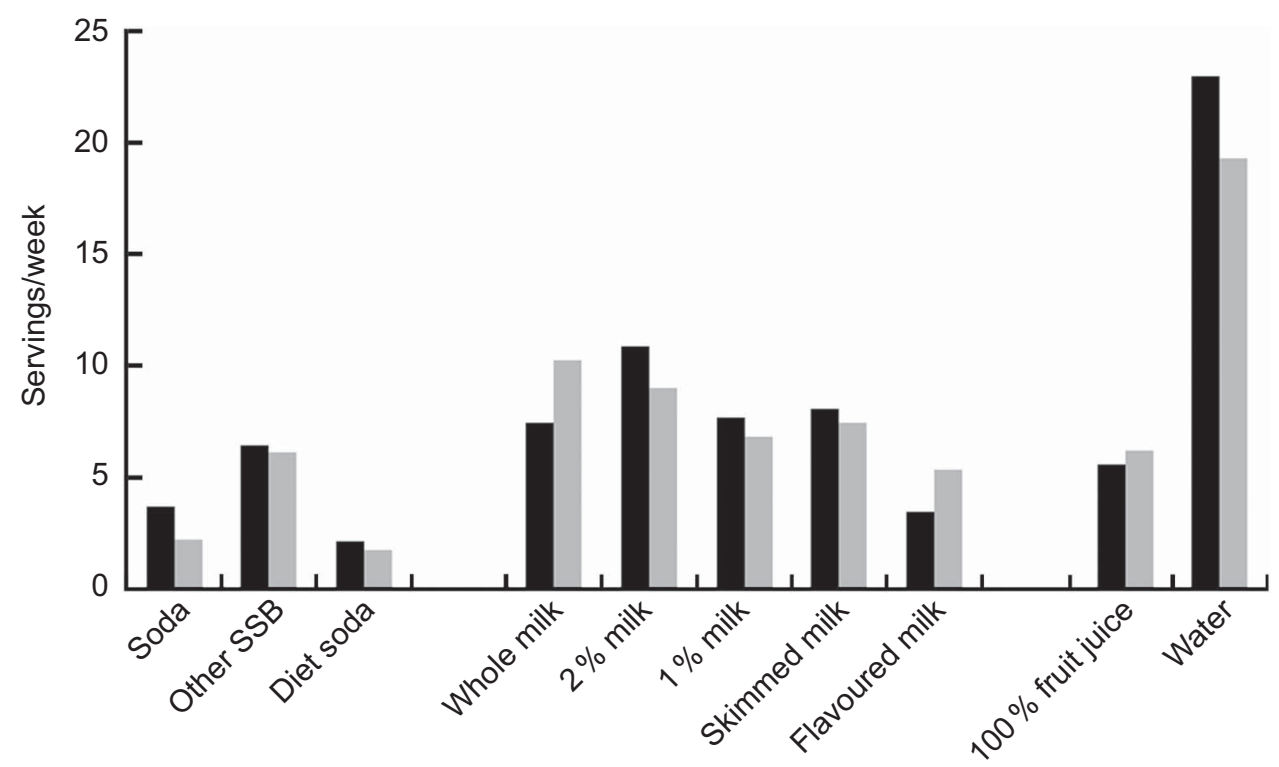

Fig. 2 Mean weekly consumption in servings $(240 \mathrm{ml})$ among obese $(\square)$ and non-obese $(\square)$ participants who consume each beverage; Mexican American children ( $n$ 319) aged 8-10 years, San Francisco Bay Area, USA (SSB, sugar-sweetened beverages) 
Table 2 Correlations between servings $(240 \mathrm{ml})$ of soda consumed in a typical week and servings of all other beverages surveyed; Mexican American children ( $n$ 319) aged 8-10 years, San Francisco Bay Area, USA

\begin{tabular}{ccccccccc}
\hline & Other SSB & Whole milk & $2 \%$ milk & $1 \%$ milk & Skimmed milk & Flavoured milk & $100 \%$ fruit juice & Water \\
\hline Soda & 0.15 & 0.08 & -0.05 & -0.014 & -0.09 & 0.09 & -0.01 & 0.014 \\
\hline
\end{tabular}

SSB, sugar-sweetened beverages.

Table 3 Results of univariate and multivariate logistic regression models with obesity (BMI $\geq 95$ th percentile) as outcome variable and servings $(240 \mathrm{ml})$ of each beverage per week as predictor among Mexican American $(n$ 319) children aged $8-10$ years $(31 \%$ obese), San Francisco Bay Area, USA

\begin{tabular}{|c|c|c|c|c|c|c|}
\hline & \multicolumn{3}{|c|}{ Univariate analysis } & \multicolumn{3}{|c|}{ Multivariate analysis } \\
\hline & OR & $95 \% \mathrm{Cl}$ & $P$ value & OR & $95 \% \mathrm{Cl}$ & $P$ value \\
\hline Soda & $1 \cdot 22$ & $1 \cdot 09,1 \cdot 36$ & 0.001 & $1 \cdot 29$ & $1 \cdot 13,1 \cdot 47$ & $<0.001$ \\
\hline Flavoured milk & 0.92 & $0.85,0.99$ & 0.03 & 0.88 & $0.80,0.96$ & 0.004 \\
\hline Whole milk & 0.92 & $0.86,0.99$ & 0.02 & 0.92 & $0.84,1.01$ & 0.07 \\
\hline $2 \%$ milk & $1 \cdot 05$ & $1 \cdot 01,1 \cdot 08$ & 0.01 & $1 \cdot 02$ & $0.98,1.07$ & NS \\
\hline Water & $1 \cdot 02$ & $1.01,1.04$ & 0.01 & $1 \cdot 02$ & $1 \cdot 0,1 \cdot 04$ & 0.06 \\
\hline Child age & $1 \cdot 02$ & $1 \cdot 00,1 \cdot 05$ & 0.04 & $1 \cdot 00$ & $0.98,1.03$ & NS \\
\hline Gender & 0.93 & $0.58,1.50$ & NS & 0.83 & $0.47,1.48$ & NS \\
\hline Child physical activity & 0.91 & $0.85,0.98$ & 0.01 & 0.93 & $0.86,1.00$ & 0.07 \\
\hline Maternal BMI & 1.09 & $1.05,1 \cdot 13$ & $<0.001$ & $1 \cdot 10$ & $1 \cdot 05,1 \cdot 15$ & $<0.001$ \\
\hline Maternal acculturation & $1 \cdot 23$ & $0.98,1.56$ & 0.08 & $1 \cdot 22$ & $0.90,1.66$ & NS \\
\hline Maternal occupational status & $0 \cdot 88$ & $0.78,0.99$ & 0.04 & 0.92 & $0.79,1.08$ & NS \\
\hline
\end{tabular}

obesity. Potential confounding variables that were associated with obesity in univariate analyses with $P<0 \cdot 1$ were: child age, child physical activity (percentage of time in moderate-to-vigorous activity), maternal BMI, maternal acculturation and maternal occupational status (Table 3). Other potential confounding variables not associated with obesity were: gender, fast-food consumption, weekly screen time, maternal education, maternal country of origin and household income. The beverage consumption variables and covariates that were associated with obesity, as well as age and gender, were entered in a multivariate analysis. In the multivariate logistic regression model, soda consumption remained significantly associated with increased odds of obesity and flavoured milk consumption remained significantly associated with lower odds of obesity (Table 3). For flavoured milk consumption, the adjusted odds ratio for obesity was $0 \cdot 88$. For soda consumption, the adjusted odds ratio was $1 \cdot 29$. Thus, for each additional serving of soda $(240 \mathrm{ml})$ consumed weekly, the odds of obesity increased by $29 \%$. Of the covariates in our model, maternal BMI was the only variable to retain significance in the multivariate analysis $(P<0 \cdot 001)$, while child moderate-to-vigorous physical activity neared significance $(P=0 \cdot 07)$.

\section{Discussion}

In this sample of Mexican American children aged 8-10 years, we found high rates of overweight and obesity. We also found that consumption of soda and other SSB was common. Nearly all of the children also consumed some form of milk, and $80 \%$ consumed $100 \%$ fruit juice. Our analyses revealed that soda consumption was associated with obesity after controlling for multiple potential confounders. For each additional $240 \mathrm{ml}$ serving of soda per week, the odds of obesity increased by $29 \%$. We also found that flavoured milk consumption was associated with lower odds of obesity. In univariate analysis, whole milk consumption was associated with lower odds of obesity and both water and $2 \%$ milk were associated with increased odds of obesity. However, these variables did not remain significant in an adjusted model. Consumption of $100 \%$ fruit juice, SSB other than soda, $1 \%$ milk and non-fat milk were not associated with obesity.

The prevalences of overweight and obesity in the current sample were higher than national averages for Mexican American children aged 6-11 years ${ }^{(1)}$. The rate of obesity among mothers in our study was also higher than national averages ${ }^{(35)}$. The higher rates of obesity in the children in our sample compared with NHANES data may be due to the relatively older age of the child participants (all children were aged 8 years or older). It is also possible that parents of overweight and obese children and parents who are themselves overweight may have been more interested in participating in a study on dietary practices than parents of normal weight children.

Our finding that soda consumption was associated with obesity is consistent with previous work in younger populations of Latino children. Warner et al. ${ }^{(8)}$ found that 2-year-old Mexican American children who consumed one or more sodas daily were more likely to be obese than those who consumed no soda. Similarly, a study of Latino children aged 2-4 years living in Los Angeles 
discovered that those who consumed two or more beverages with added sugar on a daily basis had increased odds of obesity ${ }^{(5,6)}$. Ariza et al. $^{(5)}$ reported that 5- and 6-year-old Latino children who consumed drinks containing sugar (soda, fruit punch and atole) on a daily basis were more likely to be overweight than those who did not. In contrast to our findings, Rosas et al. ${ }^{(27)}$ did not find that either soda or other sweetened drink consumption was associated with overweight in 5-year-old Mexican American children and Wilson et $a l^{(28)}$ found that the percentage of total energy intake from soda was not predictive of obesity in a large cohort of low-income Latino children aged 4-19 years.

Our study adds to the growing evidence linking soda consumption with childhood obesity. One reason why SSB such as soda may contribute to obesity is that energy consumed in liquid form may not produce the same sensation of satiety as energy from solid food and hence may not be compensated for with reduction in later intake $^{(36)}$. In our study, we did not find an association between consumption of SSB other than soda with obesity. This may be because our 'other SSB' category comprised a wide range of beverages with different sugar and energy contents, whereas most soda brands have relatively similar energy content. It is important to note that the consumption of SSB has also been directly linked to the metabolic syndrome and type 2 diabetes, independent of its association with obesity ${ }^{(37)}$. In a meta-analysis of studies conducted with adults, those who consumed one or more SSB per day were found to have a $26 \%$ increased risk of diabetes compared with those who consumed one or fewer sodas per week $^{(37)}$. Higher SSB consumption has also been linked to higher systolic blood pressure in adolescents ${ }^{(38)}$. Thus, SSB consumption may be a risk factor for future disease, irrespective of BMI.

Our finding of an association between flavoured milk consumption and lower odds of obesity has not been previously reported. While the sugar and fat contents of flavoured milk vary from brand to brand, flavoured milks generally have more energy per unit volume than nonflavoured milk. Thus, it may be that parents of lean children in our population were more comfortable serving their child a relatively higher energy beverage. We also found that whole milk consumption was significantly associated with a lower risk of obesity in univariate analysis and neared significance in our multivariate analysis $(P=0 \cdot 07)$. Three previous studies have found an association between whole milk consumption and lower odds of obesity in children ${ }^{(16,28,39)}$. One possible explanation for these findings is that the fat content of whole milk promotes satiety and thus reduces overall energy consumption. As all of these studies were cross-sectional rather than longitudinal, it is also possible that lean children were more likely to consume higherfat dairy products because their parents were not actively attempting to restrict energy and fat in their diets. However, three longitudinal studies of adults have found reduced weight gain and improved measures of adiposity over time in those consuming high-fat dairy products ${ }^{(20)}$. Longitudinal studies in children are needed to further substantiate the link between high-fat dairy consumption and lower risk of obesity and to determine the direction of the association.

Of note, we did not find an association between screen time and obesity in the present study. The link between excess television viewing time and obesity in children has been shown in several prior studies ${ }^{(5,40,41)}$. It is possible that our measure of screen time was inaccurate because it required the child to estimate total time spent in various screen time activities. Alternatively, it may be that diet is a more important risk factor for obesity in this population than sedentary time.

There are several strengths to our study. These include the large sample size, the in-home interview format and the inclusion of a wide array of beverages. Furthermore, we were able to control for multiple potential confounders in our analyses. Another strength of our study is that it addresses an important and still controversial question regarding the link between beverage consumption and obesity in a population with a high prevalence of overweight and obesity. An important limitation of the study is that it used a cross-sectional design. Thus, it is not possible to determine the direction of causality in the associations we uncovered. Additionally, as our predictor variables were determined through a parent interview, it is possible that some parents answered in a way that they thought was socially desirable and may have reported lower consumption of certain beverages that they considered to be unhealthy.

\section{Conclusion}

We found that soda consumption is an independent predictor of obesity in Mexican American children aged 8-10 years. Interventions to prevent obesity and other related conditions in Mexican American children should target reducing the consumption of soda. These interventions should begin prior to school age to promote the establishment of healthy beverage consumption patterns.

\section{Acknowledgements}

Sources of funding: This study was supported by grant R01 HL084404 from the National Heart, Lung, and Blood Institute. Conflicts of interest: All authors state that they have no conflicts of interest. Authors' contributions: A.L.B. conducted data analysis and drafted the manuscript. J.T. contributed to study design, data analysis and edited the manuscript. N.F.B. contributed to study design and edited the manuscript. C.P. contributed to study design and edited the manuscript. L.C.G. contributed to study design and edited the manuscript. Acknowledgements: The authors acknowledge the contributions of Dr Irene Takahashi and Dr Jennifer Cho who assisted with recruiting participants. 


\section{References}

1. Ogden CL, Carroll MD, Kit BK et al. (2012) Prevalence of obesity and trends in body mass index among US children and adolescents, 1999-2010. JAMA 307, 483-490.

2. Whitaker RC, Wright JA, Pepe MS et al. (1997) Predicting obesity in young adulthood from childhood and parental obesity. $N$ Engl J Med 337, 869-873.

3. L'Allemand-Jander D (2010) Clinical diagnosis of metabolic and cardiovascular risks in overweight children: early development of chronic diseases in the obese child. Int J Obes (Lond) 34, Suppl. 2, S32-S36.

4. Wang YC, Bleich SN \& Gortmaker SL (2008) Increasing caloric contribution from sugar-sweetened beverages and $100 \%$ fruit juices among US children and adolescents, 1988-2004. Pediatrics 121, e1604-e1614.

5. Ariza AJ, Chen EH, Binns HJ et al. (2004) Risk factors for overweight in five- to six-year-old Hispanic-American children: a pilot study. J Urban Health 81, 150-161.

6. Davis JN, Whaley SE \& Goran MI (2012) Effects of breastfeeding and low sugar-sweetened beverage intake on obesity prevalence in Hispanic toddlers. Am J Clin Nutr 95, 3-8.

7. Lim S, Zoellner JM, Lee JM et al. (2009) Obesity and sugarsweetened beverages in African-American preschool children: a longitudinal study. Obesity (Silver Spring) 17, 1262-1268.

8. Warner ML, Harley K, Bradman A et al. (2006) Soda consumption and overweight status of 2-year-old MexicanAmerican children in California. Obesity (Silver Spring) 14, 1966-1974.

9. Newby PK, Peterson KE, Berkey CS et al. (2004) Beverage consumption is not associated with changes in weight and body mass index among low-income preschool children in North Dakota. J Am Diet Assoc 104, 1086-1094.

10. O'Connor TM, Yang SJ \& Nicklas TA (2006) Beverage intake among preschool children and its effect on weight status. Pediatrics 118, e1010-e1018.

11. Vanselow MS, Pereira MA, Neumark-Sztainer D et al. (2009) Adolescent beverage habits and changes in weight over time: findings from Project EAT. Am J Clin Nutr 90, 1489-1495.

12. Bachman CM, Baranowski T \& Nicklas TA (2006) Is there an association between sweetened beverages and adiposity? Nutr Rev 64, 153-174.

13. Forshee RA, Anderson PA \& Storey ML (2008) Sugarsweetened beverages and body mass index in children and adolescents: a meta-analysis. Am J Clin Nutr 87, 1662-1671.

14. Malik VS, Schulze MB \& Hu FB (2006) Intake of sugarsweetened beverages and weight gain: a systematic review. Am J Clin Nutr 84, 274-288.

15. Mattes RD, Shikany JM, Kaiser KA et al. (2011) Nutritively sweetened beverage consumption and body weight: a systematic review and meta-analysis of randomized experiments. Obes Rev 12, 346-365.

16. Barba G, Troiano E, Russo $\mathrm{P}$ et al. (2005) Inverse association between body mass and frequency of milk consumption in children. Br J Nutr 93, 15-19.

17. Olivares S, Kain J, Lera L et al. (2004) Nutritional status, food consumption and physical activity among Chilean school children: a descriptive study. Eur J Clin Nutr 58, 1278-1285.

18. Tanasescu M, Ferris AM, Himmelgreen DA et al. (2000) Biobehavioral factors are associated with obesity in Puerto Rican children. J Nutr 130, 1734-1742.

19. Kelishadi R, Zemel MB, Hashemipour M et al. (2009) Can a dairy-rich diet be effective in long-term weight control of young children? J Am Coll Nutr 28, 601-610.

20. Louie JC, Flood VM, Hector DJ et al. (2011) Dairy consumption and overweight and obesity: a systematic review of prospective cohort studies. Obes Rev 12, e582-e592.
21. Spence LA, Cifelli CJ \& Miller GD (2011) The role of dairy products in healthy weight and body composition in children and adolescents. Curr Nutr Food Sci 7, 40-49.

22. Dennison BA, Rockwell HL \& Baker SL (1997) Excess fruit juice consumption by preschool-aged children is associated with short stature and obesity. Pediatrics 99, 15-22.

23. Faith MS, Dennison BA, Edmunds LS et al. (2006) Fruit juice intake predicts increased adiposity gain in children from low-income families: weight status-by-environment interaction. Pediatrics 118, 2066-2075.

24. Melgar-Quinonez HR \& Kaiser LL (2004) Relationship of child-feeding practices to overweight in low-income Mexican-American preschool-aged children. $J$ Am Diet Assoc 104, 1110-1119.

25. Skinner JD \& Carruth BR (2001) A longitudinal study of children's juice intake and growth: the juice controversy revisited. J Am Diet Assoc 101, 432-437.

26. O'Neil CE, Nicklas TA, Rampersaud GC et al. (2011) One hundred percent orange juice consumption is associated with better diet quality, improved nutrient adequacy, and no increased risk for overweight/obesity in children. Nutr Res 31, 673-682.

27. Rosas LG, Guendelman S, Harley K et al. (2011) Factors associated with overweight and obesity among children of Mexican descent: results of a binational study. J Immigr Minor Health 13, 169-180.

28. Wilson TA, Adolph AL \& Butte NF (2009) Nutrient adequacy and diet quality in non-overweight and overweight Hispanic children of low socioeconomic status: the Viva la Familia Study. J Am Diet Assoc 109, 1012-1021.

29. Rockett HR, Breitenbach M, Frazier AL et al. (1997) Validation of a youth/adolescent food frequency questionnaire. Prev Med 26, 808-816.

30. Stallings V \& Fung E (1999) Clinical nutritional assessment of infants and children. In Modern Nutrition in Health and Disease, 9th ed., pp. 885-893 [M Shils, J Olson, M Shike et al., editors]. Philadelphia, PA: Lippincott, Williams and Wilkins.

31. Robinson TN (1999) Reducing children's television viewing to prevent obesity: a randomized controlled trial. JAMA 282, 1561-1567.

32. Marin G \& Gamba R (1996) A new measurement of acculturation for Hispanics: the Bidimensional Acculturation Scale for Hispanics (BAS). Hisp J Behav Sci 18, 297.

33. Hollingshead A (1975) Four Factor Index of Social Status. Working Paper. New Haven, CT: Department of Sociology, Yale University.

34. Kuczmarski RJ, Ogden CL, Grummer-Strawn LM et al. (2000) CDC growth charts: United States. Adv Data issue $314,1-27$.

35. Flegal KM, Carroll MD, Kit BK et al. (2012) Prevalence of obesity and trends in the distribution of body mass index among US adults, 1999-2010. JAMA 307, 491-497.

36. Pan A \& Hu FB (2011) Effects of carbohydrates on satiety: differences between liquid and solid food. Curr Opin Clin Nutr Metab Care 14, 385-390.

37. Malik VS, Popkin BM, Bray GA et al. (2010) Sugar-sweetened beverages and risk of metabolic syndrome and type 2 diabetes: a meta-analysis. Diabetes Care 33, 2477-2483.

38. Nguyen S, Choi HK, Lustig RH et al. (2009) Sugarsweetened beverages, serum uric acid, and blood pressure in adolescents. J Pediatr 154, 807-813.

39. LaRowe TL, Moeller SM \& Adams AK (2007) Beverage patterns, diet quality, and body mass index of US preschool and school-aged children. J Am Diet Assoc 107, 1124-1133.

40. Anderson SE \& Whitaker RC (2010) Household routines and obesity in US preschool-aged children. Pediatrics 125, 420-428.

41. Lumeng JC, Rahnama S, Appugliese D et al. (2006) Television exposure and overweight risk in preschoolers. Arch Pediatr Adolesc Med 160, 417-422. 